\title{
Realidade do aleitamento materno cruzado em Maternidade Filantrópica de
}

\section{Aracaju, Sergipe}

\author{
Reality of cross-nursing in a Philanthropic Maternity Hospital in Aracaju, Sergipe \\ Realidad de la lactancia cruzada en una Maternidad Filantrópica en Aracaju, Sergipe
}

Recebido: 11/10/2021 | Revisado: 19/10/2021 | Aceito: 20/10/2021 | Publicado: 22/10/2021

Giovanna Pimentel Oliveira Silva

ORCID: https://orcid.org/0000-0002-4981-8466 Universidade Tiradentes, Brasil

E-mail: giovanna.pimente196@gmail.com

Izailza Matos Dantas Lopes

ORCID: https://orcid.org/0000-0001-9752-5628 Universidade Tiradentes, Brasil

E-mail: izailzamatos@gmail.com

José Rodrigo Santos Silva

ORCID: https://orcid.org/0000-0002-1918-7122 Universidade Federal de Sergipe, Brasil E-mail: rodrigo.ufs@gmail.com

Kaylane Fernanda Lima Santos ORCID: https://orcid.org/0000-0002-9503-1453 Universidade Tiradentes, Brasil E-mail: kaylanefe92@gmail.com

Alessandro Santos Ferreira

ORCID: https://orcid.org/0000-0003-1781-4759 Universidade Tiradentes, Brasil E-mail: alessandro180598@gmail.com

Winny Mikaelly Gonçalves Resende ORCID: https://orcid.org/0000-0002-6801-1270 Universidade Tiradentes, Brasil E-mail: resendewinny@gmail.com

\begin{abstract}
Resumo
Objetivo: Analisar o conhecimento de mulheres sobre a prática do aleitamento cruzado. Metodologia: Estudo observacional, prospectivo e analítico realizado em Maternidade Filantrópica de Aracaju, de agosto a novembro de 2021. A população utilizada na pesquisa consistiu em mães encaminhadas ao alojamento conjunto e ambulatório de especialidades do Hospital e Maternidade Santa Isabel, sendo aplicado questionário pelos pesquisadores. Resultados: A prevalência do aleitamento cruzado foi de $49,16 \%$, sendo que $31,11 \%(n=42)$ amamentaram uma ou mais crianças que não o seu filho e $18,05 \%$ (n=24) tiveram seu filho amamentado por uma ou mais nutrizes. $62,22 \%$ delas não sabiam o que era aleitamento cruzado. 52,59\%, encontrava-se na faixa etária entre 21 a 30 anos. Quanto à raça, a maior parte se configurou como não branca. Moravam em zona rural 16,30\%. Menos da metade, 40,60\%, declarou-se como casada ou união estável. 74,81\%, vivia com menos de um salário a 1 salário mínimo ao mês e também não exerciam atividade formal remunerada, 87,41\%. 65,19\% delas recebiam auxílio Bolsa Família. Apenas 5,19\% nível superior completo ou incompleto. Comparando as variáveis, foram notados dois P-valores com níveis de significância, $\mathrm{p}=0,002$ e $\mathrm{p}=0,031$, correspondendo a se as mães conheciam o risco do aleitamento cruzado ou se elas tinham sido amamentadas por outra mulher além da própria mãe, respectivamente. Conclusão: Apesar de ser uma prática proibida no Brasil, o aleitamento cruzado é ainda recorrente e nota-se escassez de informação acerca do tema.
\end{abstract}

Palavras-chave: Amamentação cruzada; Aleitamento materno; Amamentação; Leite materno.

\begin{abstract}
Objective. This study aims to assess the knowlegde of the women about the practice of crossfeeding. Methods. Observational, prospective and analytical study carried out in a Philanthropic Hospital and Maternity in Aracaju SE, from August to November 2021. The population used in the research consisted of mothers referred to rooming-in and specialized outpatient clinic of the Hospital and Maternity Santa Isabel, being applied a questionnaire by the researchers. Results. The prevalence of cross-breastfeeding was $49.16 \%$, considering that $31.11 \%(\mathrm{n}=42)$ of the mothers breastfed one or more children other than their child and $18.05 \%(n=24)$ had their child breastfed for one or more nursing mothers. $62.22 \%$ of them did not know what cross-breastfeeding was. 52, 59\% were aged between 21 and 30 years. As for the race, most were configured as non-white. $16.30 \%$ lived in rural areas. Less than half, $40.60 \%$, declared themselves to be married or in a stable relationship. $74.81 \%$, lived with less than one salary at one minimum
\end{abstract}


wage per month and also did not have a formal paid job, 87.41\%. 65.19\% of them received Bolsa Família aid. Only $5.19 \%$ had completed or incomplete higher education. When the variables were compared, two P-values were noted with significance levels, $\mathrm{p}=0.002$ and $\mathrm{p}=0.031$, corresponding to whether mothers knew the risk of cross-breastfeeding or whether they had been breastfed by a woman other than the mother, respectively. Conclusion. Despite being prohibited in Brazil, crossfeeding is still recurrent, in high percentages and there is a lack of information on the subject.

Keywords: Cross-nursing; Breastfeeding; Breast-feeding; Breast milk.

\section{Resumen}

Objetivo: Analizar el conocimiento de las mujeres sobre la práctica de la lactancia materna cruzada. Metodología: Estudio observacional, prospectivo y analítico realizado en la Maternidad Filantrópica de Aracaju, de agosto a noviembre de 2021. La población utilizada en la investigación estuvo constituida por madres derivadas de régimen de alojamiento conjunto y ambulatorio especializado del Hospital y Maternidad Santa Isabel, con un cuestionario aplicado por los investigadores. Resultados: La prevalencia de la lactancia materna cruzada fue de 49,16\%, con $31,11 \%(\mathrm{n}=42)$ amamantó a uno o más niños además de su hijo y $18,05 \%(\mathrm{n}=24)$ tuvo a su hijo amamantado por una o más madres lactantes. El 62,22\% de ellos no sabía qué era la lactancia materna cruzada. El 52,59\% tenían entre 21 y 30 años. En cuanto a la raza, la mayoría se configuraron como no blancas. El 16,30\% vivía en zonas rurales. Menos de la mitad, el 40,60\%, se declaró casada o en una relación estable. El 74,81\% vivía con menos de un salario a 1 salario mínimo mensual y no tenía un trabajo formal remunerado, 87,41\%. El 65,19\% de ellos recibieron ayudas de Bolsa Família. Solo el 5,19\% de educación superior completa o incompleta. Al comparar las variables, se observaron dos valores de $\mathrm{p}$ con niveles de significancia, $\mathrm{p}=0,002$ y $\mathrm{p}=0,031$, correspondientes a si las madres conocían el riesgo de la alimentación cruzada o si habían sido amamantadas por una mujer diferente a la madre. respectivamente. Conclusión: A pesar de ser una práctica prohibida en Brasil, la lactancia materna cruzada sigue siendo recurrente y falta información sobre el tema.

Palabras clave: Lactancia materna cruzada; Amamantamiento; Amamantamiento; La leche materna.

\section{Introdução}

O leite materno é a melhor fonte de nutrição para o crescimento e desenvolvimento do bebê, além de trazer inúmeros benefícios ao binômio mãe-filho (Can; Ünülü, 2019; Kaur; Raghuvanshi; Kang, 2019). Ele também é necessário para proteção imunológica e reduz a morbi-mortalidade infantil, sendo, dessa forma, recomendado pela Organização Mundial da Saúde (OMS), o aleitamento materno exclusivo até os seis meses de vida do bebê. Porém, existem situações em que a mãe (seja por sua morte ou por não ter leite suficiente) ou o filho (por ser prematuro ou baixo peso) inviabilizam o aleitamento materno. Diante tais exceções, a Organização Mundial da Saúde (OMS) recomenda que a criança receba leite ordenhado da própria mãe ou receba leite de um banco de leite. Isso reduz o risco de infecções graves em geral, dentre elas a enterocolite necrotizante, principalmente nos prematuros. Bebês que nunca foram amamentados exclusivamente apresentam internações mais prolongadas e mais visitas ao médico quando comparados aos bebês que são amamentados (Kaur; Raghuvanshi; Kang, 2019).

O leite materno pode transmitir doenças conhecidas e desconhecidas e por isso, quando se é doado ou compartilhado, ele deve ser pasteurizado antes de ser dado à criança. O número de UTINS que utilizam o leite materno pasteurizado das doadoras dos bancos de leites aumentou nos últimos anos, porém muitas instituições ainda não adotaram essa medida seja por questões de custo, falta de disponibilidade, resistência dos pais em aceitar o leite doado, questões culturais, religiosas ou legais (Sauer et al., 2016).

Existem formas de aleitamento em que o leite ofertado ao lactente não é produzido pela mãe biológica, mas que não podem ser consideradas como formas de aleitamento cruzado. A primeira delas é o aleitamento feito com leite doado através do Banco de Leite Humano (BLH), onde ele é pasteurizado, esterilizado e selecionado após passar por um processo de controle biológico. A outra forma é a relactação, na qual o leite é produzido pela mãe adotiva através de estimulação, após a mãe e o filho terem realizado avaliação médica para garantir a aptidão para a amamentação (Santiago; Mattar, 2007).

A ama de leite, definida como a mulher que amamenta outra criança, já existia muito antes da introdução da mamadeira, da fórmula e foi alternativa mais comum para a amamentação escolhida pela mãe biológica por muito tempo ao 
longo da história. A amamentação cruzada, nome dado a esta prática, data antes de 2000 a.C., quando era uma forma de necessidade, evoluindo para atitude de escolha (950 a.C a 1800 d.C.) quando as amas de leite eram contratadas, tornando-se uma profissão, com leis destinadas a regular sua prática. Durante a Idade Média e o Renascimento, apesar de objeções, as amas de leite passaram a ser uma profissão respeitada e as famílias que tinham condições de arcá-la, tornavam-se grande sinônimo de status social. A amamentação cruzada continuou até o surgimento da mamadeira no século XIX. Com introduções de novos métodos alternativos para alimentação, a amamentação cruzada rapidamente declinou estendendo-se até o século XX (Stevens; Patrick; Pickler, 2009). Culturalmente, o aleitamento cruzado é aceito no Brasil devido à tradição das amas de leite do século XIX que amamentavam as crianças das famílias com as quais viviam (Koutsoukos, 2009).

Apesar da consciência acerca dos riscos de transmissão de doenças, dificuldades de encontrar amas de leite, estigmatização da sociedade, disponibilidade de leite animal e melhorias nas mamadeiras, a amamentação cruzada encontra-se ainda presente, sendo utilizada como um método de alimentação contínuo pelas sociedades (Stevens; Patrick; Pickler, 2009; Al-Naqeeb et al., 2000). Lima et al. (2021) em sua revisão sistemática verificou a prevalência do aleitamento cruzado de $8,2 \%$ a $19,2 \%$ em estudos internacionais e no Brasil de $15,3 \%$ a $53,8 \%$.

O aleitamento cruzado é uma prática que ocorre quando a criança é amamentada por leite que não é produzido por sua mãe e sim por outra mulher. Esta prática de lactação é caracterizada tanto por uma nutriz que amamenta uma criança que não é seu filho, quando uma mãe permite que seu filho seja amamentado por outra mulher (Vieira et al., 2001). A amamentação cruzada pode ocorrer de forma indireta, quando a nutriz faz a ordenha retirando o próprio leite para algum recipiente, porém sem fazer nenhum tipo de análise ou processo de esterilização, tratamento ou controle microbiológico, ou de forma direta, amamentando o filho de outra mulher diretamente no seu seio (Carvalho, 2013).

De acordo com a Organização Mundial da Saúde (OMS), quando a mulher não pode ofertar seu leite para o filho em condições excepcionais, por não ser adequado ou não estar disponível, deve-se escolher a melhor alternativa de acordo com as circunstâncias individuais e coletivas. As alternativas são: amamentação com leite obtido em banco de leite humano, substituto ao leite humano, leite ordenhado de outra lactante ou amamentação realizada por uma lactante saudável (OMS, 2010; OMS 2003). Todavia, no Brasil, a amamentação cruzada é uma prática proibida de acordo com a lei, conforme estabelecido pela Portaria n 1.016 de 26 de Agosto de 1993, dispondo sobre a proibição da amamentação cruzada seja pela nutriz ao amamentar filhos que não seus ou que permitam que os seus sejam amamentados por outra nutriz. Além disso, a amamentação cruzada não tem sido recomendada, pois estudos evidenciaram através do leite materno as crianças podem adquirir diversas doenças causadas por agentes como o Citomegalovirus (cmv), Humanimunodeficiencyvirus (HIV); Human T lymphotropicvirus (HTLV) entre outros. Mesmo com exames pré-natais negativos, essa lactante pode estar na janela imunológica, dando um falso negativo (Vieira; Issler; Teruya, 2007).

O modo como a mãe alimenta seus filhos é influenciado pelos familiares, parceiros e amigos, assim como a forma de ela amamentar é estruturada com base na interação dela com a comunidade, familiares e seu cotidiano. $\mathrm{O}$ aleitamento materno é condicionado socio-culturalmente e é resultado da impregnação de determinantes e ideologias do modo de viver. Portanto, pode ser que cartazes e orientação não sejam o bastante para impedir o aleitamento cruzado uma vez que esta trata-se de uma prática incutida culturalmente em nosso meio social (Von Seehausen; Oliveira; Boccolini, 2017).

Esse estudo teve como objetivo analisar o conhecimento de mulheres sobre a prática do aleitamento cruzado, através de levantamento de dados após aplicação de questionário a mulheres que não sejam primigestas em uma maternidade filantrópica localizada em Aracaju, tendo, por meio da apresentação dos resultados e da discussão, agregar conhecimento sobre a temática para a sociedade. 


\section{Metodologia}

Estudo observacional, prospectivo e analítico realizado em Maternidade Filantrópica de Aracaju SE a partir da aplicação de um questionário com base em dados relevantes da literatura, no período de três meses, com o intuito de avaliar o conhecimento de mulheres sobre a prática da amamentação cruzada.

A população utilizada na pesquisa consistiu em mulheres que já eram mães ou estavam à espera de um filho (multíparas) e eram encaminhadas ao alojamento conjunto e ambulatório de especialidades em Maternidade Filantrópica, em Aracaju SE, admitidas no período compreendido entre agosto de 2021 a novembro de 2021.

A amostra foi por conveniência envolvendo todas as mulheres que já eram mães ou que estavam gestantes, mas não em sua primeira gestação, que concordaram e assinaram o TCLE ou o TALE atendidas no alojamento conjunto e ambulatório de especialidades da Maternidade do estudo. Foram excluídas aquelas primigestas que foram internadas para curetagem ou tiveram como desfecho um feto morto.

O método de coleta de dados foi efetuado através da aplicação de um questionário pelos pesquisadores. Os dados sociodemográficos obtidos foram posteriormente transcritos para uma planilha confeccionada pelos pesquisadores para traçar o perfil socioeconômico da mãe. Além disso, foi aplicado um questionário abordando os antecedentes obstétricos da mãe com finalidade de obter mais informações sobre as variáveis correlacionadas à amamentação cruzada. Por fim, foi aplicado um questionário referente ao conhecimento da amostra pesquisada sobre a amamentação cruzada.

$\mathrm{O} \mathrm{n}$ amostral foi pela demanda das lactantes no alojamento conjunto e que não eram primigestas, como também aquelas que estavam em acompanhamento com seus filhos no ambulatório de especialidades.

O resumo descritivo das variáveis foi feito através de frequência simples e percentual. A análise inferencial foi feita através dos testes de Qui-Quadrado e Exato de Fisher, de acordo com o pressuposto de cada teste. Os resultados foram exibidos em termos de frequência e percentual (calculado em função de cada linha). As análises foram feitas no software R, versão 4.1.0, e o nível de significância adotado foi de 5\%.

Foi explicado às mulheres participantes elegíveis da pesquisa e, somente após leitura, explicação e assinatura do Termo de Consentimento Livre e Esclarecido, tais mulheres foram incluídas. O projeto foi submetido à apreciação e avaliação do Comitê de Ética em Pesquisa da Universidade Tiradentes aprovado sob número do CAAE 44262620.3.0000.5371 e com número de Parecer 4.862.200. Como também houve aprovação do Núcleo de Educação e Pesquisa da Maternidade do estudo e os pesquisadores garantem sigilo, confiabilidade e fidedignidade acerca dos dados estudados. (fonte: TNR 10 - justificado espaço 1,5).

\section{Resultados}

Considerando as variáveis demográficas, 52,59\% das entrevistadas encontravam-se na faixa etária entre 21 a 30 anos, 12,59\% possuíam 20 anos ou menos e 34, $81 \%$ possuíam 30 anos ou mais.

Quanto à raça, a maior parte se configurou como não branca, sendo 71,85\% parda, 16,30\% preta e 11,85\% branca. Moravam em zona urbana $83,70 \%$ e 16,30\% em zona rural. Menos da metade, $40,60 \%$, declararam-se como casada ou união estável.

Quanto ao número de habitantes na casa, 14,07\% moravam com 1 a 2 pessoas, $57,78 \%$ com 3 a 4 e $28,15 \%$ com 5 ou mais. A maioria das mães entrevistadas, configurando $74,81 \%$, vivia com menos de um salário a 1 salário mínimo ao mês e também não exerciam atividade formal remunerada, 87,41\%. 65,19\% delas recebiam auxílio Bolsa Família e apenas 5,19\% delas possuíam nível superior completo ou incompleto (Quadro 1). 
Quadro 1: Perfil epidemiológico das mães pesquisadas no Hospital Santa Isabel, segundo características sociodemográficas. Aracaju, Sergipe, 2021.

\begin{tabular}{|c|c|c|}
\hline Variável/Categoria & $\mathbf{N}$ & Percentual \\
\hline \multicolumn{3}{|l|}{ Faixa Etária } \\
\hline 20 anos ou menos & 17 & 12,59 \\
\hline 21 a 30 anos & 71 & 52,59 \\
\hline 31 anos ou mais & 47 & 34,81 \\
\hline \multicolumn{3}{|l|}{ Raça } \\
\hline Branca & 16 & 11,85 \\
\hline Parda & 97 & 71,85 \\
\hline Preta & 22 & 16,30 \\
\hline \multicolumn{3}{|l|}{ Moradia } \\
\hline Zona rural & 22 & 16,30 \\
\hline Zona urbana & 113 & 83,70 \\
\hline \multicolumn{3}{|l|}{ Estado Civil } \\
\hline Casada ou união estável & 54 & 40,60 \\
\hline Solteira/Divorciada/Viúva & 79 & 59,40 \\
\hline \multicolumn{3}{|l|}{ Quantas pessoas moram com você? } \\
\hline 1 ou 2 & 19 & 14,07 \\
\hline 3 ou 4 & 78 & 57,78 \\
\hline 5 ou mais & 38 & 28,15 \\
\hline \multicolumn{3}{|l|}{ Renda } \\
\hline 0 Menos de um a 1 salário mínimo $\quad(\mathrm{R} \$ 1.045,00)$ & 101 & 74,81 \\
\hline 1 a 2 salários mínimos ( $\mathrm{R} \$ 1.045,00-2.090,00)$ & 27 & 20,00 \\
\hline Mais de 2 salários mínimos (> R \$2.090,00) & 7 & 5,19 \\
\hline \multicolumn{3}{|l|}{ Recebe ajuda do Bolsa Família? } \\
\hline Não & 47 & 34,81 \\
\hline Sim & 88 & 65,19 \\
\hline \multicolumn{3}{|l|}{ Grau de escolaridade? } \\
\hline $1^{\circ}$ Grau Completo ou Incompleto & 51 & 37,78 \\
\hline $2^{\circ}$ Grau Completo ou Incompleto & 77 & 57,04 \\
\hline Nível Superior Completo ou Incompleto & 7 & 5,19 \\
\hline \multicolumn{3}{|l|}{ Exerce atividade formal remunerada? } \\
\hline Não & 118 & 87,41 \\
\hline Sim & 17 & 12,59 \\
\hline
\end{tabular}

Legenda: N - Número amostral. Fonte: Autores.

No Quadro 2 a maioria das mães possuía de 1 a 2 filhos, fez o pré-natal completo, relata ter sido orientada sobre aleitamento materno durante o pré-natal, fez aleitamento materno exclusivo (AME) durante os 6 primeiros meses e ofertou a primeira mamada na primeira hora de vida. 
Quadro 2: Perfil epidemiológico das mães pesquisadas no Hospital Santa Isabel, segundo características obstétricas. Aracaju, Sergipe, 2021.

\begin{tabular}{|c|c|c|}
\hline Variáveis/ Categoria & $\mathbf{N}$ & Percentual \\
\hline \multicolumn{3}{|l|}{ 1. Quantos filhos? } \\
\hline 1 a 2 & 77 & 57,04 \\
\hline 3 a 4 & 38 & 28,15 \\
\hline 5 a 6 & 14 & 10,37 \\
\hline mais de 6 & 6 & 4,44 \\
\hline \multicolumn{3}{|c|}{ 2. Qual o número de consultas pré-natal realizadas? } \\
\hline 1 a 2 & 3 & 2,24 \\
\hline 3 a 4 & 12 & 8,96 \\
\hline 5 a 6 & 13 & 9,70 \\
\hline mais de 6 & 106 & 79,10 \\
\hline \multicolumn{3}{|c|}{$\begin{array}{l}\text { 4. Recebeu orientação sobre aleitamento materno durante } \\
\text { o pré-natal? }\end{array}$} \\
\hline Não & 42 & 31,58 \\
\hline Sim & 91 & 68,42 \\
\hline \multicolumn{3}{|c|}{$\begin{array}{l}\text { 5. Qual profissional te orientou sobre o aleitamento } \\
\text { materno? }\end{array}$} \\
\hline Agente de saúde & 3 & 3,33 \\
\hline Enfermeiro & 50 & 55,56 \\
\hline Médico & 24 & 26,67 \\
\hline Outro & 9 & 10,00 \\
\hline Técnico ou auxiliar de Enfermagem & 4 & 4,44 \\
\hline \multicolumn{3}{|c|}{ 6. Qual foi o tipo de aleitamento nos seis primeiros meses? } \\
\hline Aleitamento materno complementado & 18 & 13,74 \\
\hline Aleitamento materno exclusivo & 60 & 45,80 \\
\hline Aleitamento materno misto & 22 & 16,79 \\
\hline Aleitamento materno predominante & 20 & 15,27 \\
\hline Apenas fórmulas infantis & 11 & 8,40 \\
\hline \multicolumn{3}{|c|}{$\begin{array}{l}\text { 7. Você ofereceu a primeira mamada na primeira hora de } \\
\text { vida? }\end{array}$} \\
\hline Não & 15 & 11,19 \\
\hline Sim & 119 & 88,81 \\
\hline
\end{tabular}

Legenda: N - Número amostral. Fonte: Autores.

Na abordagem do questionário sobre aleitamento cruzado, uma parcela significativa das mães, 62,22\%, não sabia o que era e as que sabiam, geralmente adquiriram seu conhecimento sobre o tema com amigos, familiares e conhecidos.

A prevalência de prática de aleitamento cruzado, quando abordado nas entrevistadas, foi de 49,16\%, sendo que $31,11 \%(n=42)$ amamentaram uma ou mais crianças que não o seu filho e 18,05\% $(n=24)$ tiveram seu filho amamentado por uma ou mais nutrizes. Quanto às mães que nunca praticaram amamentação cruzada, quando elas foram questionadas se amamentariam outra criança que não seu filho, uma grande maioria de $81,72 \%$ respondeu que o faria Contrapondo os dados obstétricos, pode-se observar que apesar de altas taxas de orientação sobre aleitamento materno e pré-natal completo não tiveram influenciam sobre as baixas taxas de conhecimento acerca dos riscos da amamentação cruzada, 34,07\% e conhecimento acerca de doenças transmissíveis através do leite materno, 19,26\%.

Apesar do número significativo de praticantes de amamentação cruzada, elas revelaram terem sido amamentadas 
apenas por suas mães e menos $9 \%$ afirmou ter sido amamentada por outra mulher quando bebê. Já um alto número tinha conhecimento acerca do Banco de Leite Humano - 81,48\%, contudo poucas delas foram doadoras - 18,52\% (Quadro 3).

Quadro 3: Conhecimento das mães pesquisadas no Hospital Santa Isabel acerca da amamentação cruzada. Aracaju, Sergipe, 2021.

\begin{tabular}{|c|c|c|}
\hline Variáveis/ Categoria & $\mathbf{N}$ & Percentual \\
\hline \multicolumn{3}{|c|}{ 1. Você sabe o que é amamentação cruzada } \\
\hline Não & 84 & 62,22 \\
\hline Sim & 51 & 37,78 \\
\hline \multicolumn{3}{|c|}{ 2. Onde adquiriu o conhecimento sobre a amamentação cruzada? } \\
\hline Amigos, familiares e conhecidos & 17 & 33,33 \\
\hline Internet e televisão & 13 & 25,49 \\
\hline Outros & 14 & 27,45 \\
\hline Pré-natal & 7 & 13,73 \\
\hline \multicolumn{3}{|c|}{ 3. Você já amamentou ou forneceu o seu leite para o filho de outra pessoa? } \\
\hline Não & 93 & 68,89 \\
\hline Sim & 42 & 31,11 \\
\hline \multicolumn{3}{|l|}{ 3.3. Se não, você o faria? } \\
\hline Não & 17 & 18,28 \\
\hline Sim & 76 & 81,72 \\
\hline \multicolumn{3}{|c|}{ 4. Algum filho seu já mamou ou recebeu leite de outra mulher? } \\
\hline Não & 109 & 81,95 \\
\hline Sim & 24 & 18,05 \\
\hline \multicolumn{3}{|c|}{ 5. Você conhece os riscos da amamentação cruzada? } \\
\hline Não & 89 & 65,93 \\
\hline Sim & 46 & 34,07 \\
\hline \multicolumn{3}{|c|}{ 6. Você conhece alguma doença que é transmitida através do leite materno? } \\
\hline Não & 109 & 80,74 \\
\hline Sim & 26 & 19,26 \\
\hline \multicolumn{3}{|c|}{ 7. Você já foi amamentada por outra mulher que não a sua mãe? } \\
\hline Não & 103 & 91,96 \\
\hline Sim & 9 & 8,04 \\
\hline \multicolumn{3}{|c|}{ 8. Você conhece alguém ou já viu alguma mulher praticar amamentação cruzada? } \\
\hline Não & 58 & 42,96 \\
\hline Sim & 77 & 57,04 \\
\hline \multicolumn{3}{|c|}{ 9. Você sabe o que é o Banco de Leite Humano? } \\
\hline Não & 25 & 18,52 \\
\hline Sim & 110 & 81,48 \\
\hline \multicolumn{3}{|c|}{ 10. Você é doadora ou já doou seu leite para o Banco de Leite Humano? } \\
\hline Não & 110 & 81,48 \\
\hline Sim & 25 & 18,52 \\
\hline
\end{tabular}

Legenda: N - Número amostral. Fonte: Autores.

O Quadro 4 mostra a estatística inferencial na comparação do aleitamento materno cruzado com as variáveis da 
pesquisa. Houve significância do p nas mães que não conheciam o risco da amamentação cruzada e naquelas que foram amamentadas por outra lactante que não era a sua mãe.

Quadro 4: Análise inferencial do conhecimento acerca do aleitamento cruzado com P-valor. Aracaju, Sergipe. 2021.

\begin{tabular}{|c|c|c|c|}
\hline Variável/ Categoria & Não & Sim & P-valor \\
\hline \multicolumn{4}{|l|}{$\begin{array}{l}\text { Onde adquiriu o conhecimento sobre a } \\
\text { amamentação cruzada? }\end{array}$} \\
\hline Amigos, familiares e conhecidos & $0(0)$ & $17(100)$ & 1,000 \\
\hline Internet e televisão & $0(0)$ & $13(100)$ & \\
\hline Outros & $0(0)$ & $14(100)$ & \\
\hline Pré-natal & $0(0)$ & $7(100)$ & \\
\hline \multicolumn{4}{|l|}{$\begin{array}{l}\text { Você já amamentou ou forneceu o seu leite } \\
\text { para o filho de outra pessoa? }\end{array}$} \\
\hline Não & $62(66.7)$ & $31(33.3)$ & 0,164 \\
\hline Sim & $22(52.4)$ & 20 (47.6) & \\
\hline \multicolumn{4}{|l|}{ Se não, você o faria? } \\
\hline Não & $9(52.9)$ & $8(47.1)$ & 0,351 \\
\hline Sim & $52(68.4)$ & $24(31.6)$ & \\
\hline \multicolumn{4}{|l|}{$\begin{array}{l}\text { Algum filho seu já mamou ou recebeu leite } \\
\text { de outra mulher? }\end{array}$} \\
\hline Não & $71(65.1)$ & $38(34.9)$ & 0,126 \\
\hline Sim & $11(45.8)$ & $13(54.2)$ & \\
\hline \multicolumn{4}{|l|}{$\begin{array}{l}\text { Você conhece os riscos da amamentação } \\
\text { cruzada? }\end{array}$} \\
\hline Não & $64(71.9)$ & $25(28.1)$ & $0,002 *$ \\
\hline Sim & $20(43.5)$ & $26(56.5)$ & \\
\hline \multicolumn{4}{|l|}{$\begin{array}{l}\text { Você conhece alguma doença que é } \\
\text { transmitida através do leite materno? }\end{array}$} \\
\hline Não & $71(65.1)$ & $38(34.9)$ & 0,228 \\
\hline Sim & $13(50)$ & $13(50)$ & \\
\hline \multicolumn{4}{|l|}{$\begin{array}{l}\text { Você já foi amamentada por outra mulher } \\
\text { que não a sua mãe? }\end{array}$} \\
\hline Não & $64(62.1)$ & $39(37.9)$ & $0,031^{*}$ \\
\hline Sim & $2(22.2)$ & $7(77.8)$ & \\
\hline \multicolumn{4}{|c|}{$\begin{array}{l}\text { Você conhece alguém ou já viu alguma mulher praticar } \\
\text { amamentação cruzada? }\end{array}$} \\
\hline Não & $40(69)$ & $18(31)$ & 0,221 \\
\hline Sim & $44(57.1)$ & $33(42.9)$ & \\
\hline \multicolumn{4}{|l|}{$\begin{array}{l}\text { Você sabe o que é o Banco de Leite } \\
\text { Humano? }\end{array}$} \\
\hline Não & $18(72)$ & $7(28)$ & 0,374 \\
\hline Sim & $66(60)$ & $44(40)$ & \\
\hline \multicolumn{4}{|l|}{$\begin{array}{l}\text { Você é doadora ou já doou seu leite para o } \\
\text { Banco de Leite Humano? }\end{array}$} \\
\hline Não & $71(64.5)$ & $39(35.5)$ & 0,348 \\
\hline Sim & $13(52)$ & $12(48)$ & \\
\hline
\end{tabular}

Legenda: * - P-Valores com níveis de significância. Fonte: Autores. 


\section{Discussão}

Embora seja uma prática proibida no Brasil pelo Ministério da Saúde e contraindicada pela OMS (Vieira; Issler; Teruya, 2007; Brasil, 1993), quase metade das mães praticou o aleitamento cruzado (49,16\%). Esta prevalência foi superior à encontrada em um estudo transversal realizado em 9 unidades básicas de saúde do Rio de Janeiro no ano de 2013 (29,4\%), sendo que 10,8\% amamentaram uma ou mais crianças que não o seu filho, 9,8\% tiveram seu filho amamentado por outra nutriz e $8,8 \%$ praticaram as duas formas de aleitamento cruzado (Von Seehausen et al., 2017) e foi próxima à do estudo de Pereira et al. (2015) que revelou uma prevalência de aleitamento cruzado de 61,54\% no grupo de gestantes não nulíparas, sendo que dessas 53,84\% eram nutrizes que amamentaram filhos de outras e 17,94\% eram as que permitiram que seus filhos fossem amamentados por outra mulher.

Observa-se que em todos eles, as taxas de mulheres que amamentaram os filhos que não seus são sempre superiores àqueles referentes às mães que tiveram seus filhos amamentados por outra nutriz. No estudo de Buges, Klinger e Pereira (2020), 23,1\% das puérperas entrevistadas praticaram amamentação cruzada em gestações anteriores e 15,4\% praticaram a amamentação cruzada permitindo que seus filhos fossem amamentados por outra mulher.

Uma parcela significativa das mães praticaram amamentação cruzada, mas quanto àquelas que nunca o fizeram, quando foram questionadas se amamentariam o filho de outra pessoa, a maior parte delas respondeu que sim e, em sua pesquisa, Pereira et al (2015) observou que houve prevalência das participantes que se mostraram solícitas em ser nutriz do filho de outras mulheres independentemente de elas terem recebido informações ou não acerca dos perigos do aleitamento cruzado durante o pré-natal e serem orientadas quanto ao risco desta prática.

No estudo de Pereira et al. (2015), a faixa etária mais frequente foi a de 23 a 26 anos (30,44\%), o que confirma a tendência brasileira de fecundidade entre jovens entre 15 a 24 anos, e o grau de escolaridade mais frequente foi o de 12 a mais anos de estudo (47,82\%), corroborando com o presente estudo, que teve a taxa mais prevalente de 21 a 30 anos com $52,59 \%$ das entrevistas e o grau de estudo mais encontrado foi $2^{\circ}$ grau completo ou incompleto com 57,04\%.

Já Seehausen et al. (2017), também mostrou que a maior parte foram orientadas sobre aleitamento materno (78,7\%), se autodeclararam não brancas $(73,5 \%)$ e não trabalhavam $(63,2 \%)$. Contudo, $22,7 \%$ eram adolescentes e $77,6 \%$ tinham ensino fundamental incompleto.

Estudos verificaram a relação de características como idade entre 21 a 30 anos, raça não branca, baixa renda, médio nível de escolaridade e não exercício de atividade remunerada como fatores prevalentes, confirmando associação de indicadores de vulnerabilidade com a prática de aleitamento cruzado (Seehausen et al., 2017; Can; Ünülü, 2019).

O grau de instrução da nutriz, mostrou-se em um estudo como fator positivo para a doação de leite materno e à prática da amamentação, uma vez que um nível maior de instrução se correlaciona com maior acesso à informação e mais facilidade de entendimento das informações sobre a importância tanto da doação quanto da amamentação (Buges; Klinger; Pereira, 2020). Entretanto, observou-se que apesar de muitas mães conhecerem o Banco de Leite Humano (BLH), poucas delas afirmaram ser doadoras, o que revela que além de resistência (seja por motivos culturais, religiosos ou higiênicos), há muitas vezes a falta de comunicação entre a entidade materna e equipe de saúde (Karadag et al., 2015).

Entretanto, esta atual pesquisa, após análise estatística inferencial através dos testes de Qui-Quadrado e Fisher, utilizando um valor de significância de 5\%, encontrou pouca relação entre as variáveis demográficas e o aleitamento cruzado. Como também nas associações mais relevantes entre as demais categoriais abordadas no estudo. As duas variáveis que apresentaram ligação à prática do aleitamento cruzado, foram quando foi avaliado se as mães conheciam o risco do aleitamento cruzado, sendo encontrado um valor $\mathrm{p}=0,002$ e a quando foi questionado se elas tinham sido amamentadas por outra mulher além da própria mãe, onde obteve-se valor $\mathrm{p}=0,031$.

A forma como é conduzido o processo educativo para promoção da saúde do binômio mãe-filho no que condiz ao 
aleitamento materno, reflete como este irá se desenvolver futuramente, repercutindo inclusive na amamentação cruzada. É fundamental que para abordagem de tais temáticas, seja no pré-natal, no parto ou puerpério, o processo educativo seja promovido em forma de aconselhamento abrangendo estratégias de intervenções com orientações onde a equipe de saúde seja capaz de ouvir as necessidades não só da mãe, tampouco do binômio, mas da tríade mãe-filho-família e abrir espaço para que dúvidas possam ser tiradas, estabelecendo uma rede de canal com linguagem simples e acessível, além de ser um local de acolhimento (Gomes et al., 2020).

Consideraram-se como limitações neste presente estudo a escassez de fontes científicas acerca do tema que abordassem de forma mais específica o aleitamento cruzado, principalmente no Brasil, uma vez que grande parte das pesquisas encontradas foram realizadas na Turquia e em outros países com uma realidade cultural, religiosa e política diferente. Além disso, a principal fonte de informação obtida nesta pesquisa foram as respostas obtidas das mães entrevistadas, o que pode gerar viés de informação. Contudo, demonstra-se que esse viés de informação não foi significativo, ou seja, a consequência de associação com o desfecho não tendeu a sub ou superestimação.

\section{Conclusão}

A pesquisa demonstrou uma prevalência significativa do aleitamento cruzado entre as mães entrevistadas no ambulatório e alojamento conjunto do Maternidade do estudo, prevalência esta que se tornou mais relevante, uma vez que mesmo aquelas que nunca praticaram a amamentação cruzada, revelaram no questionário a intenção de amamentar o filho de outra mulher, caso houvesse a necessidade. Além disso, ao se avaliar o conhecimento acerca do tema, percebeu-se que, embora muitas vezes a temática seja abordada nos alojamentos do próprio hospital e haja o incentivo à não prática da amamentação cruzada, no estudo, a maioria das participantes desconhecia totalmente a respeito da questão.

A escassez de informação e o arcabouço histórico-cultural faz com que as mães não conheçam os riscos do aleitamento cruzado e perpetuem a ideia de que amamentar outra criança ou deixar seu filho ser amentado é uma forma de salvar sua vida (Von Seehausen; Oliveira; Boccolini, 2017).

É necessário orientar a mulher sobre a amamentação e para isso é necessário tempo. A consulta pré-natal é um espaço essencial para ser debatido este tema e dar a oportunidade para que a mãe possa falar sobre suas experiências e suas crenças e dessa forma conseguir garantir direcionamento sobre o aleitamento adequado.

Espera-se que os resultados desta pesquisa preencham a lacuna no que se refere à realidade do aleitamento materno cruzado. Prática que apesar de proibida no Brasil e não recomendada pela OMS, ainda é recorrente. A análise dos dados propiciará a ação preventiva da amamentação cruzada evitando possíveis complicações relacionadas à prática.

Apesar da relevância do tema ainda existe uma escassez de estudos que determinem a prática do aleitamento materno cruzado no Brasil e no mundo. Estudos futuros serão necessários para trabalhar com amostragens maiores e questionários com variáveis semelhantes e randomizados. A partir dos resultados dessas pesquisas nortear medidas preventivas para reduzir a prática do aleitamento materno cruzado que pode impactar negativamente na qualidade de vida pela transmissão de doenças como vírus HIV, human T-cell lymphotropic (HTLV), Citomegalovirus (CMV), hepatitis C virus (HCV), hepatitis B vírus (HBV) e West Nile virus.

\section{Agradecimentos}

A todas as mães participantes que tornaram esta pesquisa possível e ao Hospital e Maternidade Santa Isabel que foi o campo de estudo para a realização do trabalho. 


\section{Referências}

Al-Naqeeb, N. A., Azab, A., Eliwa, M. S., \& Mohammed, B. Y. (2000). The introduction of breast milk donation in a Muslim country. Journal of human lactation: official journal of International Lactation Consultant Association, 16(4), 346-350. doi.org/10.1177/089033440001600412.

Buges, N. M., Klinger, K. S. A., \& Pereira, R. J. (2020). New mothers and their understanding about breast milk donation. Rev. Bras. Saude Mater. Infant, 20(1), 213-225.

Can, Ş. \& Ünülü, M. (2019). Knowledge of Mother Regarding Wet Nursery and Breast Milk Banking. Ankara Medical Journal, 19 (1), 60-70. doi.org/10.17098/amj.542150.

Carvalho, M. R. (2013). Amamentação Cruzada e Amas de Leite: práticas não recomendadas. http://www.aleitamento.com/ama mentacao/conteudo.asp?cod=1561.

Gomes, C. S., Dias, M. O., Rodrigues, B. M. R. D., Peres, P. L. P., Arantes, P. C. C., \& Rodrigues, B. R. D. (2020). Amamentação cruzada no cenário da precarização do trabalho em saúde: atuação do enfermeiro [Cross-breastfeeding in the scenario of health work precarization: nurse's role] [Lactancia cruzada en el escenario de precarización del trabajo de salud: papel de la enfermera]. Revista Enfermagem UERJ, 28, e35224. doi.org/10.12957/reuerj.2020.35224.

Karadag, A., Ozdemir, R., Ak, M., Ozer, A., Dogan, D. G., \& Elkiran, O. (2015). Human milk banking and milk kinship: Perspectives of mothers in a Muslim country. Journal of tropical pediatrics, 61(3), 188-196. doi.org/10.1093/tropej/fmv018.

Kaur, M., Raghuvanshi, S., \& Kang, H. K. (2019). Knowledge and Attitude of Indian Parous Women toward Human Milk Banking. Indian journal of community medicine: official publication of Indian Association of Preventive \& Social Medicine, 44(2), 175-176. doi.org/10.4103/ijcm.IJCM_377_18.

Koutsoukos, S. S. M. (2009). 'Amas mercenárias': O discurso dos doutores em medicina e os retratos de amas - Brasil, segunda metade do século XIX. Hist. Cienc. Saude -Manguinhos, 16(2), 305-324. doi.org/10.1590/S0104-59702009000200002.

Lima, T. A., Martins, F. A., \& Ramalho, A. A. (2021). Prevalência de aleitamento cruzado no século XXI: uma revisão integrativa/ Prevalence of crossbreastfeeding in the 21st century: an integrative review. Brazilian Journal of Health Review, 4(2), 5281-5289. doi.org/ 10.34119/bjhrv4n2-101

Ministério da Saúde. (n.d.) Portaria n o 1.016, de 26 de agosto de 1993. https://bvsms.saude.gov.br/bvs/saudelegis/gm/1993/prt1016_26_08_1993.html.

Pereira, C. R. G., Pereira, W. M. M., Gonçalves, N. V., Ravena-Cañete, V., Dias, F. A., \& Tavares, C. G. M. (2015). Prevalência de aleitamento cruzado e saberes sobre esta prática. Revista Paraense de Medicina, 29(3) jul-set 2015.

Santiago, L. B, Mattar, M. J. G. (2007). Boletim Informativo da Sociedade Brasileira de Pediatria. 6. out 2006/jan 2007. Departamento Científico de Amamentação.

Sauer, C. W., \& Marc-Aurele, K. L. (2016). Parent Misidentification Leading to the Breastfeeding of the Wrong Baby in a Neonatal Intensive Care Unit. The American journal of case reports, 17, 574-579. doi.org/10.12659/ajcr.898864.

Seehausen, M. P. von, Oliveira, M. I. C. de, Boccolini, C. S., \& Leal, M. do C. (2017). Fatores associados ao aleitamento cruzado em duas cidades do Sudeste do Brasil. Cadernos de Saúde Pública, 33(4), 1-10. doi.org/10.1590/0102-311x00038516.

Stevens, E. E., Patrick, T. E., \& Pickler, R. (2009). A history of infant feeding. The Journal of perinatal education, 18(2), 32-39. doi.org/10.1624/105812409X426314.

Vieira, A. C. J., Amaral, D. F., Pedrosa, K. J, \& Ichisato, S. M. T. (2001). Conhecimento das puérperas sobre o aleitamento cruzado. Revista do Centro Universitário Barão de Mauá, 1(2), 1-12. Retrieved from http://www.baraodemaua.edu.br/comunicacao/publicacoes/jornal/v1n2/artigo03.html.

Vieira, G. O., Issler, H., \& Teruya, K. M. (2010). Amamentação e doenças maternas. In Tratado de pediatria. Barueri: Manole.

Von Seehausen, M. P., Oliveira, \& M. I. C., \& Boccolini, C. S. (2017). Fatores associados ao aleitamento cruzado. Ciência \& Saúde Coletiva, 22(5), 16731682 .

World Health Organization (WHO). (2003) Global strategy for infant and young child feeding. Geneva: WHO.

World Health Organization (WHO), Unicef, Pan American Health Organization. (2010). Haiti earthquake: Technical note on HIV and infant feeding. Geneva: WHO. 